\title{
Paralisia do nervo ocolumotor após infecção por dengue: um relato de caso
}

\author{
Oculomotor nerve palsy after dengue infection: a case report \\ Parálisis del nervio ocolumotor después de la infección por dengue: reporte de un caso \\ Amanda Perpetuo de Oliveira ${ }^{1}$, Ingrid Paula Oliveira Azevedo ${ }^{1 *}$, Letícia Andrade Souza ${ }^{1}$, Letícia \\ Vieira Moutinho Silva ${ }^{1}$, Álvaro Teixeira da Costa ${ }^{1}$.
}

\section{RESUMO}

Objetivo: Relatar um caso de paralisia extraocular completa do III par craniano, sem acometimento pupilar, após infecção por vírus da dengue. Detalhamento do caso: Trata-se de um relato de caso, de uma paciente do sexo feminino, de 36 anos, que procurou o pronto atendimento após apresentar visão turva, diplopia binocular, cefaleia de leve intensidade e ptose palpebral esquerda subitamente em maio de 2019. Em relação à história pregressa, apresentou episódio de dengue em março, confirmado por sorologia (IgM), negou outras comorbidades. Optou-se pela internação para realização de propedêutica complementar que não evidenciou alterações nos exames laboratoriais e de imagem. Foi realizado tratamento com metilprednisolona, com melhora parcial e incompleta dos déficits oculares. Foi então estabelecido o diagnóstico por exclusão de paralisia do III par craniano secundário à dengue, recebendo alta hospitalar com encaminhamento para acompanhamento ambulatorial. Considerações finais: A associação entre infecção por dengue e acometimento neurológico é descrita na literatura, sendo as neurites com paralisia de nervos cranianos pouco relatadas. Os mecanismos envolvidos nessa afecção são pouco compreendidos, sendo necessários mais estudos especialmente para uniformizar protocolos de atendimento à dengue que apresentem tais complicações.

Palavras-chave: Nervo oculomotor, Paralisia, Vírus da dengue.

\begin{abstract}
Objective: To report a case of complete extraocular paralysis of the third cranial nerve, without pupillary involvement, after dengue virus infection. Details of the case: This is a case report of a 36-year-old female patient, who sought emergency care after presenting blurred vision, binocular diplopia, mild headache and sudden left eyelid ptosis in May 2019. In relation to her past history, she presented an episode of dengue in March, confirmed by serology (IgM), dening other comorbidities. We opted for hospitalization to perform complementary tests that did not show changes in laboratory and imaging exams. Treatment with methylprednisolone was performed, with partial and incomplete improvement in eye deficits. The diagnosis from exclusion of paralysis of the third cranial nerve secondary to dengue was then established, being discharged from hospital with referral for outpatient follow-up. Final considerations: The association between dengue infection and neurological impairment is described in the literature. And also, neuritis with cranial nerve palsy is rarely reported. The mechanisms involved in this condition are poorly understood, and further studies are in need, especially to standardize protocols for dengue care that present such complications.
\end{abstract}

Keywords: Oculomotor nerve, Paralysis, Dengue virus.

1 Universidade José do Rosário Vellano (UNIFENAS), Belo Horizonte - MG.

*E-mail: ingridpaulaa@gmail.com

SUBMETIDO EM: 8/2020

ACEITO EM: 9/2020

PUBLICADO EM: 10/2020 


\section{RESUMEN}

Objetivo: Informar un caso de parálisis extraocular completa del tercer nervio craneal, sin afectación pupilar, después de la infección por el virus del dengue. Detalles del caso: Este es un informe del caso de una paciente de 36 años, que buscó atención de emergencia después de presentar visión borrosa, diplopía binocular, dolor de cabeza leve y ptosis repentina del párpado izquierdo, en mayo. Con respecto a la historia previa, presentó un episodio de dengue en marzo, confirmado por serología ( $\lg M)$, negando otras comorbilidades. Optamos por la hospitalización para realizar pruebas complementarias que no mostraron cambios en los exámenes de laboratorio y de imágenes. Se realizó tratamiento con metilprednisolona, con mejoría parcial e incompleta de los déficits oculares. Luego, se estableció el diagnóstico por exclusión de la parálisis del tercer nervio craneal secundario por dengue, dado de alta del hospital con derivación para seguimiento ambulatorio. Consideraciones finales: La asociación entre la infección por dengue y el deterioro neurológico se describe en la literatura, y rara vez se informa neuritis con parálisis del nervio craneal. Los mecanismos involucrados en esta afección son poco conocidos y se necesitan más estudios, especialmente para estandarizar los protocolos de atención del dengue que presentan tales complicaciones.

Palabras clave: Nervio oculomotor, Parálisis, Virus del dengue.

\section{INTRODUÇÃO}

A dengue é um importante problema de saúde pública mundial, com respectivo impacto econômico e sobrecarga do sistema de saúde (ESTOFOLETE CF, et al., 2019). A Organização Mundial de Saúde (OMS) estima que $2 / 5$ da população mundial esteja em risco de infecção por dengue (PUCCIONI-SOHLER M, et al., 2013). Quase 400 milhões de indivíduos são infectados anualmente, desses 96 milhões apresentam sintomas clínicos relevantes com mortalidade de aproximadamente 2,5\% dos acometidos ( $\mathrm{LI} \mathrm{G-H}$, et al., 2017).

A infecção pelo vírus da dengue possui elevada prevalência em países de clima tropical, entre eles o Brasil. Até junho de 2020, foram notificados 874.093 casos prováveis de dengue no país. Entretanto, é importante destacar que houve uma modificação no cenário das notificações, a curva epidemiológica de 2020, inicialmente superior à 2019, sofreu um declínio condizente ao mesmo período dos primeiros registros de COVID-19 no país, uma provável subnotificação pode estar relacionada aos esforços de combate à pandemia (MINISTÉRIO DA SAÚDE, 2020).

O vírus da dengue é RNA positivo, fita simples, do gênero Flavivirus e transmitido por mosquitos Aedes $\mathrm{sp}$, possui quatro diferentes sorotipos (DENV1-4). Inicialmente o vírus era considerado não neurotrópico, entretanto, há uma ascensão no número de evidências recentes que demonstram o oposto. Nos últimos anos apesar de raras $(1-1,5 \%)$ as manifestações neurológicas da dengue têm sido cada vez mais relatadas, surgem entre 2 e 30 dias após o início da febre e sofrem influência direta da localização da lesão (PUCCIONI-SOHLER M, et al., 2013; LI G-H, et al., 2017).

A sintomatologia da doença pode ser variável, desde assintomático, subclínico ao acometimento grave. Na maioria dos pacientes o quadro é autolimitado e os sintomas mais frequentes e iniciais incluem: febre alta e súbita, mialgia, artralgia, cefaleia, dor retro-orbitária, vômitos, diarreia, entre outros sintomas. O exantema maculopapular é uma manifestação característica, presente em alguns casos, assim como petéquias e/ou sangramentos de mucosas, que tendem a surgir do quarto ao sétimo dia da doença.

Diante disso, pode ser classificada em: sem sinais de alarme, com sinais de alarme e em dengue grave. Dos casos registrados em 2020 no Brasil, 663 foram considerados graves e 8.066 com sinais de alarme, dos quais 415 foram à óbito. Vale ressaltar que na presença de alterações neurológicas a dengue passa a ser considerada como grave (PUCCIONI-SOHLER M, et al., 2013; ESTOFOLETE CF, et al., 2019; MINISTÉRIO DA SAÚDE, 2020). 
Em relação ao acometimento neurológico, esse pode ser categorizado em três principais grupos: sintomas leves inespecíficos; manifestações neurológicas graves (redução de sensório, letargia, convulsões, meningismo, mielite, encefalite ou encefalopatia) e manifestações tardias (paralisia das extremidades, comprometimento da memória, síndrome de Guillain-Barré, parestesia e outras manifestações psiquiátricas). Há também relatos de neurites associadas à dengue, como neurite braquial, paralisia do nervo torácico longo, paralisia do nervo frênico, abducente, oculomotor e paralisia facial periférica em diferentes regiões do mundo (PUCCIONI-SOHLER M, et al., 2013; LI G-H, et al., 2017; VERMA R, et al., 2014).

O objetivo do presente artigo é relatar um caso de paralisia do nervo oculomotor após infecção por vírus da dengue, destacando as particularidades envolvidas e as manifestações de ptose e diplopia que possuem raros relatos na literatura.

\section{DETALHAMENTO DO CASO}

Paciente do sexo feminino, de 36 anos, natural de Belo Horizonte, procurou o pronto atendimento no dia 10 de maio de 2019 após apresentar visão turva. Os sintomas iniciaram em olho direito, evoluíram para diplopia binocular, cefaleia de leve intensidade e ptose palpebral esquerda súbita. A mesma não apresentou febre, alteração de consciência, convulsões, disfunção esfincteriana, fraqueza em membros, parestesia ou rigidez de nuca associados.

Ao exame físico neurológico, apresentava-se alerta, orientada, com linguagem e articulação vocal sem alterações, com ptose palpebral incompleta e restrição à adução e mirada inferior em olho esquerdo. O olho direito estava centralizado, sem alteração da movimentação extrínseca e a acuidade visual 20/30 bilateral (com correção).

A força e sensibilidade apendiculares estavam preservadas, sem ataxia, sem meningismos, reflexos osteotendinosos ativos e simétricos nos quatro membros, com marcha atípica. Exame físico dos demais sistemas: respiratório, cardiovascular e abdominal, dentro da normalidade. Em relação à história pregressa referiu episódio de dengue em março do mesmo ano, quadro confirmado por sorologia (lgM). Negou outras comorbidades, uso contínuo de medicamentos, alergias, tabagismo ou consumo de bebidas alcoólicas.

Diante do exposto, a paciente foi internada para realização de propedêutica complementar que não evidenciou alterações aos exames laboratoriais, sendo eles potássio sérico $(3,5 \mathrm{mEq} / \mathrm{L})$, magnésio $(1,8$ $\mathrm{mEq} / \mathrm{L})$, ureia $(32 \mathrm{mg} / \mathrm{dL})$, sódio sérico $(135 \mathrm{mEq} / \mathrm{L})$, creatinina $(0,7 \mathrm{mg} / \mathrm{dL})$, hemoglobina $(13,6 \mathrm{~g} / \mathrm{dL})$, hematócrito (39\%), global de leucócitos $(10.280 / \mu \mathrm{L}$, com $85,3 \%$ de segmentados e $10,4 \%$ de linfócitos) e plaquetas $(302.000 \mu \mathrm{L})$.

A tomografia computadorizada de crânio também se encontrava dentro da normalidade. Foram-se aventadas as hipóteses de neurite secundária ao quadro prévio de dengue e síndrome de Miller-Fisher. A análise do líquido cefalorraquidiano mostrou valores normais de glicose $(64 \mathrm{mg} / \mathrm{dL}$, sendo a glicemia de 104 $\mathrm{mg} / \mathrm{dL}$ ), proteínas $(25 \mathrm{mg} / \mathrm{dL})$, hemácias $\left(34 / \mathrm{mm}^{3}\right)$, celularidade $\left(5 / \mathrm{mm}^{3}\right)$, assim como Gram, cultura, exame micológico direto, VDRL e BAAR negativos. Realizada também ressonância magnética de encéfalo que não evidenciou alterações.

Uma vez que a paciente é jovem, não possui fatores de risco e diante dos resultados dos exames complementares apresentados, foi estabelecido o diagnóstico por exclusão de paralisia do III par craniano secundário à dengue. Optou-se assim por iniciar tratamento empírico na forma de pulsoterapia com Metilprednisolona endovenosa (1 $\mathrm{g} /$ dia durante 5 dias - 14/05 à 18/05). Houve então uma melhora parcial e progressiva dos déficits oculares.

No momento da alta, ainda apresentava-se com ptose palpebral e restrição à mobilização ocular em olho esquerdo. A paciente foi encaminhada para acompanhamento ambulatorial com neurologista. Em agosto já apresentava remissão completa da ptose (Figura 1), com total recuperação da movimentação ocular extrínseca. 
Figura 1 - Evolução da ptose palpebral à esquerda em quatro meses.
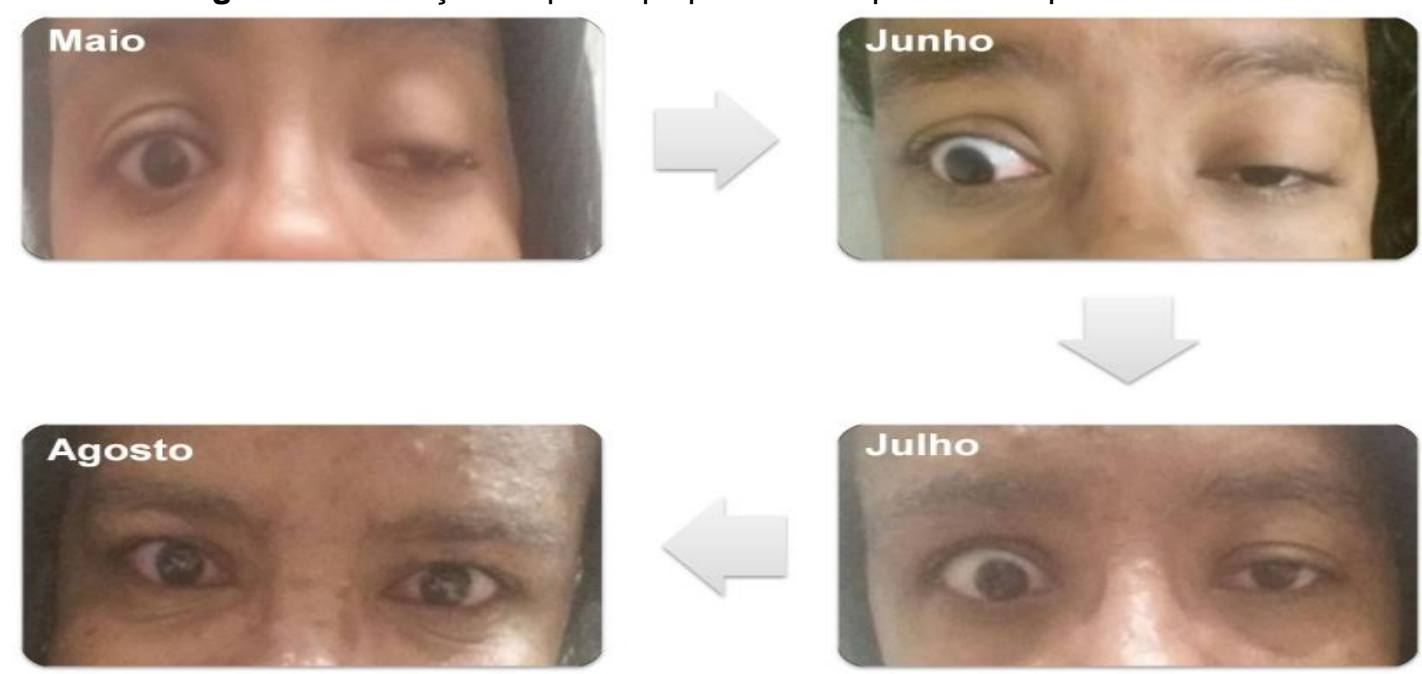

Fonte: Oliveira AP, et al., 2020.

\section{DISCUSSÃO}

A associação entre infecção por dengue e acometimento neurológico foi descrita pela primeira vez por Sanguansermsri T, et al. (1976). Esses tipos de eventos são incomuns, mas um aumento nesses relatos ocorreu nos últimos anos. Tais manifestações podem resultar de invasão viral direta no sistema nervoso devido ao seu neurotropismo ou anormalidades vasculares e metabólicas, como hemorragia intracraniana, edema cerebral, hiponatremia e anoxia cerebral. As principais manifestações neurológicas reportadas na literatura relacionadas à dengue incluem encefalite, meningite, encefalomielite aguda disseminada, mielite, miosite, Síndrome de Guillain-Barré e neuropatia dos nervos torácico longo e frênico. Embora rara, também foi relatada neurite com paralisia de nervos cranianos, principalmente envolvendo os nervos oculomotor e facial. Na maioria dos casos, o acometimento neurológico pode manifestar-se entre 2-30 dias após o início da febre e está mais associado aos sorotipos DENV2 e DENV3 (PUCCIONI-SOHLER M, et al., 2013; PUCCIONI-SOHLER M, et al., 2012; ESTOFOLETE CF, et al., 2019).

A paralisia aguda do terceiro par craniano manifesta-se por diplopia binocular vertical, horizontal ou oblíqua e com variados graus de ptose. Pode cursar também com isocoria ou midríase, cefaleia, turvação visual, dor periorbital e tontura (RAZA HK, et al., 2018; CHEN H, et al., 2019). No caso descrito foi observada ptose palpebral e paresia dos músculos da motricidade ocular extrínseca completa poupando a pupila.

A causa mais comum dessa paralisia é isquêmica, mas pode ser secundária a aneurisma, tumor, trauma $e$ infecções virais. A patogênese da neurite associada à dengue está relacionada à reação imunomediada pós-infecção, embora os mecanismos permaneçam incertos. O diagnóstico é estabelecido após exclusão de outras etiologias de neurite (RAZA HK, et al., 2018; LI G-H, et al., 2017). A paciente do presente caso apresentava sorologia positiva para dengue sem nenhuma outra causa aparente que justificasse o quadro. Além disso, houve resolução completa, o que ocorre com frequência em doenças virais. Assim, conclui-se que a paralisia do nervo oculomotor resultou da infecção pelo vírus da dengue.

Um caso semelhante foi descrito em um relato de uma paciente indiana de 14 anos que apresentou resolução espontânea completa da diplopia e parcial da ptose duas semanas após a infecção por dengue, foi tratada apenas com reposição volêmica e sintomáticos (BISWAS NM e PAL S, 2014). Em outro relato de caso de um paciente masculino de 52 anos, foi evidenciado paralisia do músculo reto lateral secundário à dengue, que evoluiu com resolução espontânea completa da diplopia apresentada (MISHRA A, et al., 2015). Outro caso de paralisia do músculo reto lateral foi descrito em um paciente do sexo masculino de 29 anos, com resolução espontânea completa do estrabismo convergente e diplopia em três meses de acompanhamento, não foi necessário uso de farmacoterapia (SHIVANTHAN MC, et al., 2012). 
Houve um relato em um paciente do sexo masculino de 31 anos de idade de perda de visão atribuída à dengue após desenvolvimento de neuropatia ótica. O paciente realizou tratamento empírico com Metilprednisolona endovenosa ( $1 \mathrm{~g} /$ dia durante 3 dias) seguido de prednisolona via oral $(1 \mathrm{mg} / \mathrm{kg}$ durante 11 dias) (SANJAY S, et al., 2008).

Foi relatado no Brasil um caso semelhante ao apresentado. A paciente foi diagnosticada com Chikungunya, com sintomas de desalinhamento ocular, diplopia e ptose bilateral. A ressonância nuclear magnética evidenciou espessamento do músculo reto medial bilateral. O quadro melhorou parcialmente após realização de pulsoterapia com corticoide (COSTA ALFA, et al., 2017).

A infecção pelo vírus Influenza tipo A (H3N2) também foi citada como causa de paralisia do nervo oculomotor unilateralmente em paciente de 44 anos. Como já sabido, o vírus influenza, assim como o da dengue, também se correlaciona a uma série de complicações neurológica, dentre as quais polineurite, meningite, encefalopatia e síndrome de Guillain-Barré.

Neste caso, o raro acometimento do nervo foi confirmado através da RNM intra-orbital e da positividade de anticorpos antigangliosídeos. O tratamento foi de forma conservadora (sem administração de medicamentos) e os sintomas oculares se reverteram completamente após um mês (SENDA J, et al., 2019).

Um estudo observacional restrospectivo realizado por Park KA et al. (2019), avaliou 15 pacientes com paralisia idiopática do terceiro e sexto pares cranianos que foram acompanhados por 10-13 meses. Oito pacientes apresentaram paralisia do sexto par craniano, seis pacientes, paralisia do terceiro par craniano (dois parciais e quatro completos), e um paciente com paralisia completa do terceiro e sexto pares cranianos. Cinco dos 6 pacientes com paralisia do terceiro par craniano receberam tratamento intravenoso com metilprednisolona com redução gradual por via oral. Dos 8 pacientes com paralisia do sexto par craniano, três receberam prednisolona oral por três a quatro semanas, enquanto os outros cinco não receberam nenhum tratamento. Em geral, os pacientes obtiveram boa resposta e bom prognóstico com o tratamento com esteróides. Onze pacientes evoluíram com recuperação total em um período de alguns dias a um ano.

Em outro estudo retrospectivo, conduzido por Chen et al. (2019), foram avaliados 121 pacientes com paralisia unilateral do terceiro par craniano hospitalizados no Hospital of Xuzhou Medical University entre outubro de 2014 e outubro de 2015. Apenas um dentre os 121 pacientes apresentou paralisia do oculomotor por encefalite de tronco cerebelar de causa viral.

A hipótese foi corroborada pela presença de leve aumento da pressão do líquido cefalorraquidiano, bem como pela discreta elevação das proteínas e celularidade do líquor. Foram administradas drogas anti-virais e foi oferecido tratamento suportivo, com remissão completa dos sintomas após 6 meses de acompanhamento.

Ter tido uma boa resposta a corticoterapia indica a possibilidade de um mecanismo neuropático imunomediado. Contudo, como observado, em diversos casos o quadro neuro-oftalmológico regrediu espontaneamente. Tal análise levanta o questionamento da real necessidade de intervenção médica nos casos em questão. A literatura ainda é controversa em relação ao uso de corticoterapia, sendo uma opção de tratamento nos casos refratários (VERMA R, et al., 2014).

A epidemia de dengue no Brasil é um dos principais problemas de saúde pública enfrentados atualmente. A fisiopatologia das manifestações neurológicas secundárias à dengue permanece indefinida devido à escassez de literatura acerca desse tema, apesar de existirem fortes indícios de envolvimento de mecanismos imunomediados.

Ainda que existam relatos de cura espontânea da neurite e seus déficits oculares, entendemos que é válido a corticoterapia, diante da análise risco $\mathrm{x}$ benefício de cada paciente. Até o presente estudo, não há relatos na literatura de outro tipo de terapia para o caso, além de pulsoterapia com corticoide. Assim, são necessários mais estudos a fim de compreender os mecanismos envolvidos nessa afecção, especialmente para uniformizar protocolos de atendimento à dengue que apresentem tais complicações. 


\section{AGRADECIMENTOS}

À paciente pelo interesse em contribuir para a realização desse relato de caso.

À Beatriz Coelho pelo auxílio na tradução.

\section{REFERÊNCIAS}

1. BISWAS NM, PAL S. Oculomotor nerve palsy in dengue encephalitis - a rare presentation. Indian J Med Res, 2014; 140(6): 793-4.

2. $\mathrm{CHEN} \mathrm{H}$, et al. The aetiologies of unilateral oculomotor nerve palsy: a clinical analysis on 121 patients. Somatosens Mot Res, 2019; 36(2):102-108.

3. COSTA ALFA, et al. Third Cranial Nerve Palsy after a Chikungunya Virus Infection. Strabismus, 2017; 25(4): 172-175.

4. ESTOFOLETE CF, et al. Unusual clinical manifestations of dengue disease - Real or imagined? Acta Trop, 2019; 199:105134.

5. LI G-H, et al. Neurological Manifestations of Dengue Infection. Front Cell Infect Microbiol, 2017; 7(499): 1-13.

6. MINISTÉRIO DA SAÚDE. Monitoramento dos casos de arboviroses urbanas transmitidas pelo Aedes (dengue, chikungunya e Zika) Semanas Epidemiológicas 1 a 26 de 2020. Secretaria de Vigilância em Saúde, 2020; 51(28): 18.

7. MISHRA A, et al. Lateral rectus palsy in a case of dengue fever. Med J Armed Forces India, 2015; 71(Suppl 1): S101S103.

8. PARK KA, et al. Idiopathic third and sixth cranial nerve neuritis. Jpn J Ophthalmol, 2019; 63(4):337-343.

9. PUCCIONI-SOHLER M, et al. Dengue: a new challenge for neurology. Neurol Int, 2012; 4(3): e15.

10. PUCCIONI-SOHLER M, et al. Neurological complications in dengue infection: a review for clinical practice. Arq Neuropsiquiatr, 2013; 71(9B): 667-671.

11. RAZA HK, et al. The aetiologies of the unilateral oculomotor nerve palsy: a review of the literature. Somatosens Mot Res, 2018; 35(3-4): 229-239.

12. SANGUANSERMSRI T, et al. Acute encephalopathy associated with dengue infection. Bangkok: Seameo Tropmed, 1976; 10-11.

13. SANJAY S, et al. Optic neuropathy associated with dengue fever. Eye (Lond), 2008; 22(5):722-4.

14. SENDA J, et al. Acute Unilateral Isolated Oculomotor Nerve Palsy in an Adult Patient with Influenza A. Intern Med, 2019; 58:433-436.

15. SHIVANTHAN MC, et al. Paralytic squint due to abducens nerve palsy: a rare consequence of dengue fever. BMC Infect Dis, 2012; 12(156).

16. VERMA R, et al. Neurological manifestations of dengue infection: A review. J Neurol Sci, 2014; 346(1-2): 26-34. 